\title{
An Economic Study of the US Post-9/11 Aviation Security
}

\author{
James Ford"1, Ardeshir Faghri1, Dian Yuan1, Saumabha Gayen² \\ ${ }^{1}$ Department of Civil and Environmental Engineering, University of Delaware, Newark, DE, USA \\ ${ }^{2}$ Lyles School of Civil Engineering, Purdue University, West Lafayette, IN, USA \\ Email: faghri@udel.edu
}

How to cite this paper: Ford, J., Faghri, A. Yuan, D., \& Gayen, S. (2020). An Economic Study of the US Post-9/11 Aviation Security. Open Journal of Business and Management, $8,1923-1945$.

https://doi.org/10.4236/ojbm.2020.85118

Received: July 13, 2020

Accepted: August 4, 2020

Published: August 7, 2020

Copyright (c) 2020 by author(s) and Scientific Research Publishing Inc. This work is licensed under the Creative Commons Attribution International License (CC BY 4.0).

http://creativecommons.org/licenses/by/4.0/ (c) (i) Open Access

\begin{abstract}
The Aviation Security world changed drastically following the terrorist attacks of September 11th, 2001. In this paper we look at 1) the changes that occurred to the aviation security sector and 2) how the United States aviation security compares to other parts of the world. Currently the United States has the most expensive aviation security infrastructure in the world. The main motivation of this topic was to find out why the United States was spending so much and assessing whether its aviation security sector was economically efficient. In this paper the authors provide the history of aviation security and the changes that took place post 9/11. A cost breakdown is presented and whether the amount of money being spent is worth the benefits received is discussed. This study also compares the United States' aviation security to that of Europe and Canada. These comparisons analyze how the total expenditure for the U.S. Transportation Security Administration (TSA) is similar/dissimilar to the aviation security expenditures in Europe and Canada. Recommendations for future budgets and tax revenues are also made. Overall, it is concluded that the amount of TSA's spending on aviation security is justified.
\end{abstract}

\section{Keywords}

Aviation Security, Post 9/11 Security, Economic Efficiency, Cost Breakdown

\section{Introduction, History, \& Technology}

The events of September 11th, 2001 represent by far the largest and most shocking realization to date of the ever-evolving threat of terrorist attacks against aviation. The attacks demonstrated how civilian aircraft could be used as weapons to kill large numbers of civilians and destroy assets on the ground. This created 
mass panic over the vulnerabilities of the civil aviation system and led to sweeping and significant changes in the design, provision and financing of aviation security throughout the world (Blalock et al., 2007; Elias, 2009; Poole, 2008). Since 2001, governments all over the world have created new organizations to implement airport security systems, and there have been massive investments in both technology and the hiring and training of security personnel (Blalock, et al., 2007; O'Connor, 2016). Through all these changes and increases in security costs, airports and airlines have faced new challenges in managing passenger throughput, minimizing delays, and improving passenger experience. Overall, the average cost of airfare for domestic flights has increased little (Bureau of Transportation Statistics, n.d.). However, the government, the general public, and the air transportation industry have borne most of the economic expenditures of these new security investments (9/11 Commission, 2004; Airport security repercussions due to the September 11 attacks, n.d.; Gordon et al., 2005; International Air Transport Association, 2006; US Department of Transportation, 2003).

The Aviation Security Sector is probably one of the United States' most scrutinized sectors in today's world (Maynard \& Robbins, 2009). This demands the inquiry of whether or not the U.S. government is spending too much on aviation security, and if that spending is actually preventing attacks. But the U.S. government takes the approach of "We need to be right $100 \%$ of the time, while they (terrorists) need to be right only one time".

The United States needs to have an economically efficient and safe aviation security system because it is the most traveled country in terms of passenger traffic (International Civil Aviation Organization, n.d.). Figure 1 shows that since 1950 the total amount of global passengers per year has been exponentially increasing. Figure 2 further highlights the recent air passenger growth from 2008 to 2018. In 2018 the total number of global passengers traveling per year reached 8.8 Billion (Airports Council International, 2019). Figure 3 indicates that the United States has 3 of the top 10 busiest passenger airports in the

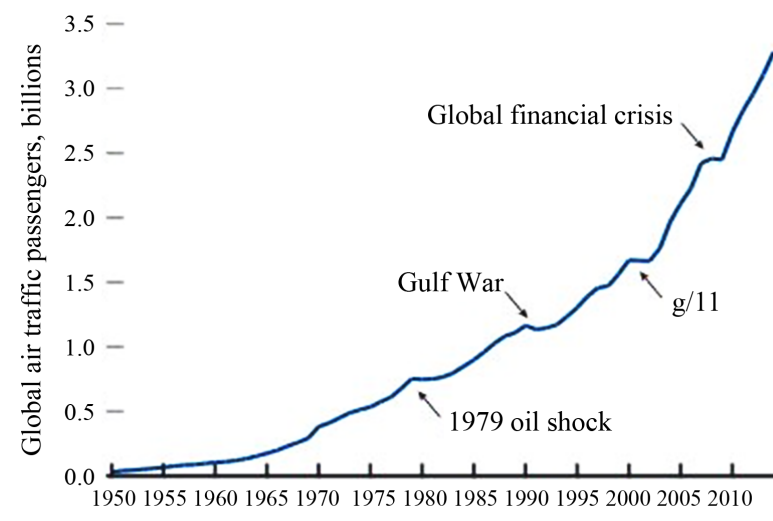

Source: IATA.

Figure 1. Total global air passengers in billions (Oxley \& Jain, 2015). 


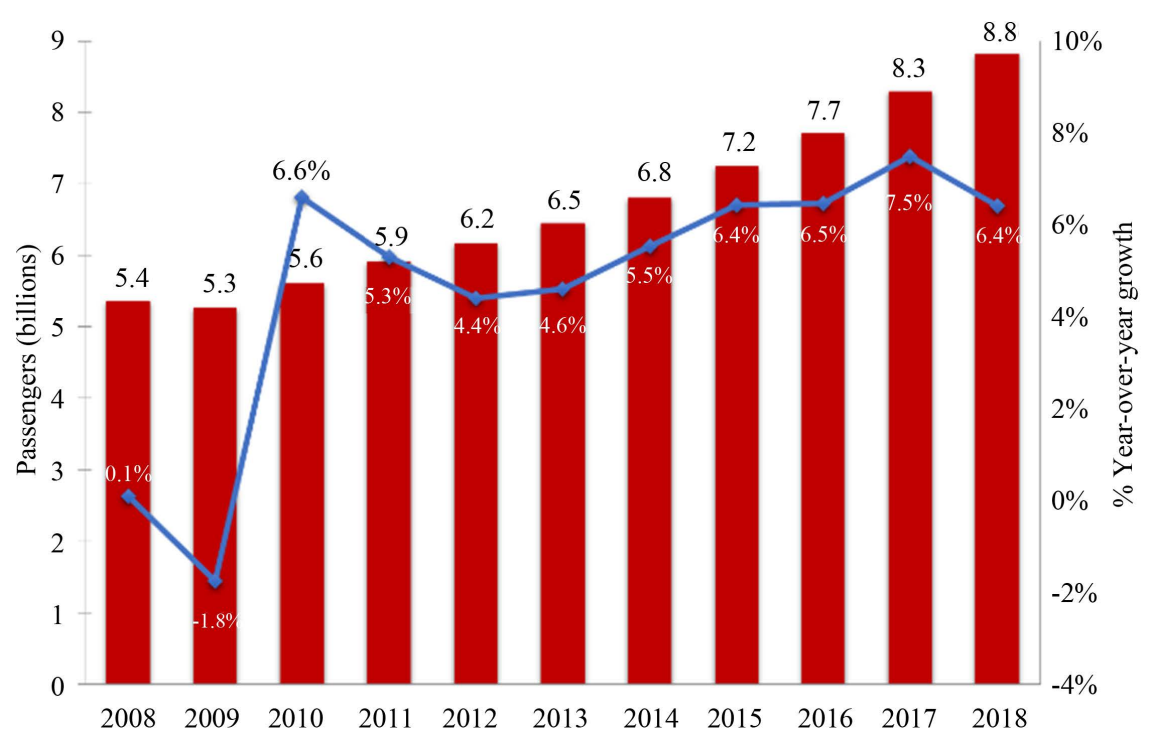

Figure 2. Global air passenger growth from 2008-2018 (Gittens, 2019).

\begin{tabular}{|c|c|l|c|c|}
\hline \multirow{2}{*}{$\begin{array}{c}\text { RANK } \\
2018\end{array}$} & \multirow{2}{*}{$\begin{array}{c}\text { RANK } \\
2017\end{array}$} & AIRPORT CITY/COUNTRY/CODE & \multicolumn{2}{|c|}{ PASSENGERS } \\
\cline { 4 - 5 } & & & $\begin{array}{c}\text { (Enplaning and } \\
\text { deplaning) }\end{array}$ & $\begin{array}{c}\text { Percent } \\
\text { change }\end{array}$ \\
\hline 1 & 1 & ATLANTA GA,US (ATL) & 107394029 & 3.3 \\
2 & 2 & BEIJING, CN (PEK) & 100983290 & 5.4 \\
3 & 3 & DUBAI, AE (DXB) & 89149387 & 1.0 \\
4 & 5 & LOS ANGELES CA, US (LAX) & 87534384 & 3.5 \\
5 & 4 & TOKYO, JP (HND) & 87131973 & 2.0 \\
6 & 6 & CHICAGO IL, US (ORD) & 82229186 & 4.4 \\
7 & 7 & LONDON, GB (LHR) & 80126320 & 2.7 \\
8 & 8 & HONG KONG, HK (HKG) & 74517402 & 2.6 \\
9 & 9 & SHANGHAI, CN (PVG) & 74006331 & 5.7 \\
10 & 10 & PARIS, FR (CDG) & 72229723 & 4.0 \\
11 & 11 & AMSTERDAM, NL (AMS) & 71053147 & 3.7 \\
12 & 16 & NEW DELHI, IN (DEL) & 69900938 & 10.2 \\
13 & 13 & GUANGZHOU, CN (CAN) & 69769497 & 6.0 \\
14 & 14 & FRANKFURT, DE (FRA) & 69510269 & 7.8 \\
15 & 12 & DALLAS/FORT WORTH TX, US (DFW) & 69112607 & 3.0 \\
16 & 19 & INCHEON, KR (ICN) & 68350784 & 10.0 \\
17 & 15 & ISTANBUL, TR (IST) & 68192683 & 6.4 \\
18 & 17 & JAKARTA, ID (CGK) & 66908159 & 6.2 \\
19 & 18 & SINGAPORE, SG (SIN) & 65628000 & 5.5 \\
20 & 20 & DENVER CO, US (DEN) & 64494613 & 5.1 \\
\hline TOP 20 FOR 2018 & & 1539332722 & 4.7 \\
\hline
\end{tabular}

Figure 3. Worldwide top 20 airports in 2018 by passenger traffic (Airports Council International, 2019).

world (Atlanta, Los Angeles, and Chicago). As the number of passengers increases, safety becomes even more important.

\section{Pre-9/11 Security}

Aviation Security in the United States prior to $9 / 11$ was much different than the security we see today. First and foremost, the Aviation Security Sector was 
privatized. Airlines themselves, along with private screening companies, hired screeners. It was not until after 2002 that the Transportation Security Administration (TSA) was created (TSA, n.d. Emerging Technology). The largest organization that oversaw aviation security in 2001 was a private company named $\mathrm{Ar}$ genbright. In 2001 they were responsible for operations at over $40 \%$ of U.S. airports, including security operations at Newark, NJ and Washington D.C., where hijackers got through their gates on $9 / 11$ (Bachman, 2002). Although there is no evidence that Argenbright or any other screening company had a failure that directly led to the breaches on that date, the attacks highlighted the various problems with aviation security at the time. The privatized aviation security sectors had no overseer and no regulations from the U.S. government. Some companies had minimal job applicant screening and hired security screeners at minimum wage. There was even a case in which they hired ex-convicts. This showed the lack of technical expertise and quality of workers prior to the $9 / 11$, the most glaring problem with security screening at US airports.

The following were aspects of security prior to the 9/11 (9/11 Commission, 2004; Bolluyt, 2018; O’Connor, 2016):

- Blades up to 4 inches were permitted on the plane;

- Baseball bats, box cutters, darts, and scissors were also allowed on the plane;

- Family members were able to go through security to the departing gate to say goodbye;

- Passengers could keep shoes on when going through security;

- Passengers could carry liquids on to the plane;

- The only security screening was a metal detector;

- No ID was required;

- Passengers would only need to arrive 30 minutes before their flight to ensure that they would make their flight.

The aviation security around the world was also much different than the aviation security that we know today. There was a mixture of private and public aviation security sectors across Europe. Similar to the United States, there were no overall mandated security rules across the European Union. However, a 2003 study showed that the quality of security personnel at European countries was much better than that of the US. The study found screening performance was affected by turnover rates, pay, and screener training. Data collected from the 1998-99 period, just a couple years before $9 / 11$, showed that US airport screeners had a higher turnover rate, lower average pay per hour, and lower hours of required training than screeners in France, Germany, UK, Netherlands, and Belgium (Fish, 2003; Hainmüller \& Lemnitzer, 2003). Additional data revealed that before September 11, in 2001, European airports screened about $80 \%$ of all baggage compared to only $10 \%$ in US airports and had significantly more explosive detection systems (EDS) machines. Overall though, aviation security in Europe was still much less regulated than it is in today's world. The European Union came together to make changes to the aviation security sector right after $9 / 11$ 
(Bouldon, 2002).

\section{Post-9/11 Security}

As mentioned, the events of September 11th, 2001 focused attention on the numerous shortcomings regarding how aviation security was being provided and regulated in the United States. The US Government reacted by ensuring that more resources were devoted to providing aviation security, as well as to research and development activities that should lead to future improvements in aviation security (US Congress, 2001). Additionally, the federal government assumed direct responsibility from the carriers and airports for the actual provision and funding of aviation security. With the enactment of Air Transportation Security Act (ATSA) of November 2001, a single body, the Transportation Security Administration (TSA) assumed overall responsibility for aviation security within the US (TSA, n.d. Mission, Transportation Security Administration). The TSA would be funded through the national government.

The federal role has moved from the setting and monitoring of security standards to one of financing and implementing the standards. This substantial enlargement of governmental involvement is in contrast to the public-private partnerships that dominate the implementation of aviation security standards in Europe. The US has followed the centralized model for aviation security since passing ATSA where the Federal government (through the TSA) has assumed responsibility for the key security activities at US airports. In the US, remuneration of key security activities is paid for primarily by the TSA out of Federal funds.

The following are aspects of U.S. security post-9/11 (Seaney, 2019):

- An official ID must be presented that matches the name on the ticket

- No liquids larger than 3.4 ounces are allowed on the plane

- All baggage goes through extensive X Ray screening

- The TSA made cockpit doors more secured

- Passengers are either screened by a metal detector or a Millimeter Wave Scanner

- Family members are no longer able to go through security and to the departing gate

- Passengers need to arrive upwards of 3 hours before international flights and at least 1.5 hours before domestic flights to ensure proper boarding

Following 9/11, the European Commission (EC) was requested to bring forward legislation on basic standards for aviation security throughout the European Union. In December 2002, the EC adopted a regulation to establish common rules in the field of aviation security across all member states, and this regulation was later updated and replaced in 2008 (European Commission, n.d.). These common standards, as listed by the EC, apply to the following areas:

- Screening of passengers, cabin baggage, and hold baggage

- Airport security

- Aircraft security 
- Screening of cargo and mail

- Screening of airport supplies

- Staff Recruitment and Training

Since the European Union is comprised of many different states, it is difficult to have one agency take control over all of the different aviation securities. However, the 2008 regulation requires each member state to identify a single authority responsible for air security within their country and requires the states and its operators to develop security programs on several levels. There are two basic models for the provision of aviation related security activities within Europe (Irish Aviation Authority, 2004):

- Centralized Model: the main security activities are primarily the responsibility of the State via a government body (CAA, Ministry of Transport, police force, etc.). This is broadly the current situation in 11 States (Austria, Finland, Germany, Iceland, Italy, Luxembourg, Norway, Portugal, Spain, Sweden and Switzerland).

- Decentralized model: the main security activities are provided by the airport authorities under the supervision of the relevant authority (normally the CAA). These activities could either be provided by the airport directly or outsourced to a third party. This is the current situation in 6 member States (Belgium, Denmark, France, Greece, Ireland, and Netherlands) and the United Kingdom.

Canada also made changes to their aviation security. In Canada, the federal government created the Canadian Air Transport Security Authority (CATSA) as an independent agency with a mandate to test and implement new security technologies and to oversee the training and standards of security personnel (CATSA, n.d.; Government of Canada, 2011). Unlike the US, in Canada, private market firms supply the security personnel.

Prior to 9/11 there were many terrorist-related incidents worldwide. Figure 4 depicts the annual deaths due to aviation attacks, and it shows that there were several major attacks during 1970-2000. However, after 9/11, the graph shows that the number of annual deaths has drastically decreased and remained relatively small. This can be attributed to the many systematic changes in aviation security that decrease and thwart possible attacks. In the US and in other countries, there was immense security investment and government regulations, such increased screening and reinforced cockpit doors, which have since helped reduce the number of attacks.

\section{Current \& Future Technologies}

Prior to 9/11, not much advanced technology was used to screen passengers. Following the attacks, the TSA prioritized the development and use advanced technology to screen passengers, as they wanted to screen all passengers while keeping security lines efficient. In addition to the Transportation Security Officers inside airports, the following technologies are currently used to screen and process passengers: 


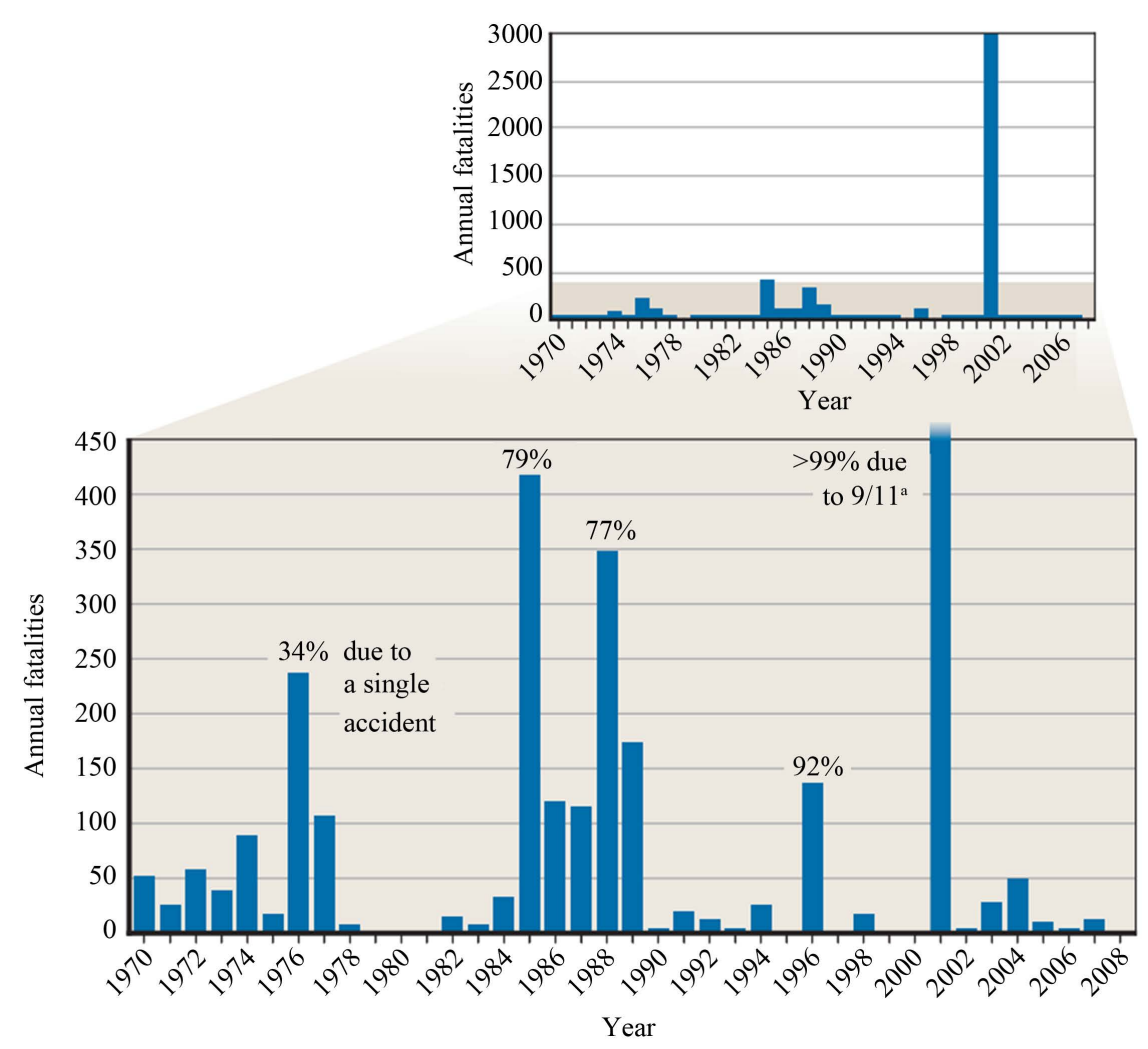

Figure 4. Fatalities form attacks on aviation by year, 1970-2008 (Jackson \& Frelinger, 2012).

- Metal Detectors

- Millimeter Wave Scanners

- 2D X-Rays for carry-on bag screening

- CT scanners for checked baggage

- Manual searches and the use of canines

The technology that is being used today is considered advanced when comparing it to the technology that was used prior to 9/11. Still, the technology used now is neither $100 \%$ effective nor $100 \%$ efficient. The TSA plans to continue to make advancements in the technological field to provide the highest level of security at an efficient rate.

The TSA initiated a public-private partnership to harness the ingenuity and entrepreneurial of both sectors and help meet the mission of protecting the traveling public (TSA, 2017). They did so by establishing the Innovation Task Force to help identify and pilot exceptional security technologies, including those that are still on the drawing board. Through this initiative, three new technologies are close to being instituted into our current aviation security in both the US and various European countries. These three technologies are (Katko, 2017; Vora, 2017; TSA, n.d. Security Fee)

- Enhanced 3D Computed Tomography (CT) Scanners

- Automated Screening Lanes 
- Biometric Fingerprint Identification

The Enhanced 3D CT Scanners will be used to screen checked bags and carry-on bags without requiring the removal of select travel items. Using this technology, passengers can leave liquids, gels, and technology (laptops etc.) in bags to increase process speeds. This technology can collect double the amount of information than the conventional equipment used (2D X-Ray). It can also automatically detect explosives, including liquid ones.

Automated Screening lanes will be used for carry-on bags. There will be an automatic conveyer belt used to screen these bags. One of the top priorities of the screening process is to detect $100 \%$ of threats while minimizing the screening and processing times of passengers. Deploying successful Automated Screening lanes will increase the passenger flow by $30 \%$.

Finally, the Biometric Fingerprint Identification technology is currently being tested in Atlanta and Denver. This technology verifies a person's identity through their fingerprint, facial features, and physical characteristics. This new technology can also pull up a boarding pass. The Biometric Fingerprint Identification can potentially improve both the level of security and efficiency for screening at airports.

\section{Survey of Literature}

\section{Cost Breakdown of Aviation Security in the United States}

The Unites States government funds the Transportation Security Administration as a part of the Homeland Security Department. In 2018, the TSA budget of $\$ 7.5$ billion made up $10.7 \%$ of the entire homeland security budget (USDHS, 2017). With the demand for new technologies to increase the effectiveness and efficiency of security screening, this budget is slowly increasing, as the president's budget for the TSA in 2019 was over $\$ 7.7$ billion (USDHS, 2019). The Homeland Security Department spends about $\$ 70.6$ Billion per year. Table 1 and Table 2 show a breakdown of the Total 2018 Budget.

Table 1 shows the overall budget broken down into three main categories. Table 2 shows an extensive breakdown of the overall budget.

Further Breakdown of the Budget:

- \$3 Billion for Transportation Security Officers (TSO’s)

- \$200 Million for Transportation Screening Technologies

Table 1. TSA FY 2018 prevent terrorism and enhance security budget (USDHS, 2017).

\begin{tabular}{cc}
\hline \multicolumn{2}{c}{ 2018 TSA Budget } \\
\hline Operations and Support & Amount \$ \\
\hline Procurement, Construction, and Improvements & $7,258,724,000$ \\
Research and Development & $303,314,000$ \\
Total & $20,190,000$ \\
\hline
\end{tabular}


Table 2. TSA Fiscal Year (FY) 2018 budget (USDHS, 2017).

\begin{tabular}{|c|c|}
\hline \multicolumn{2}{|c|}{2018 TSA Budget Breakdown } \\
\hline & Amount \$ \\
\hline Aviation Screening Operations & $4,822,911,000$ \\
\hline Aviation Screening Infrastructure & $57,213,000$ \\
\hline TSA Pre-Check Fee & $136,900,000$ \\
\hline Aviation Security Capital Fund (ASCF) & $250,000,000$ \\
\hline Other Operations and Enforcement & $1,325,996,000$ \\
\hline Infrastructure for Other Operations & $16,291,000$ \\
\hline Air Cargo/Certified Cargo Screening Program & $5,200,000$ \\
\hline Alien Flight School & $5,200,000$ \\
\hline Commercial Aviation and Airport Fee & $8,000,000$ \\
\hline FAA Certificates Fee & - \\
\hline Freight Rail Fee & - \\
\hline General Aviation at DCA Fee & 560,000 \\
\hline Hazardous Materials Endorsement Fee & $20,200,000$ \\
\hline Other Security Threats Assessments Fee & 50,000 \\
\hline Public Transportation and Passenger Rail Fee & - \\
\hline TWIC Fee & $64,449,000$ \\
\hline Mission Support & $869,258,000$ \\
\hline Total & $7,582,228,000$ \\
\hline
\end{tabular}

- $\$ 116.6$ Million to provide training for new TSA employees

- $\$ 83.5$ million for TSA's intelligence operations

- $\$ 10$ million to replace IT infrastructure

- $\$ 900$ Million for Air Marshal Program

Since $9 / 11$, USA has spent over $\$ 100$ billion in aviation security, significantly more than other countries during this period. This massive expenditure requires us to explore why the US is spending so much more than other countries and whether or not this spending is justifies, as well as possibilities to reduce the budget and still provide the same security. Figure 5 depicts that since 9/11 we have begun to spend more and more on aviation security (shown in bottom table). The chart shows that the money appropriated to the TSA has increased from $\$ 4.3$ Billion to $\$ 7.2$ Billion from 2002 to 2011. Since about 2008, the budget has remained in the $\$ 7$ Billion range, and this amount has stayed fairly consistent over the last decade. Additionally depicted is a breakdown of total TSA funding, which shows that on average, only about $20 \%-30 \%$ of the expenses are funded by passenger security fees. This number will be compared to other countries in a later section.

Cost Breakdown of Aviation Security across the World 


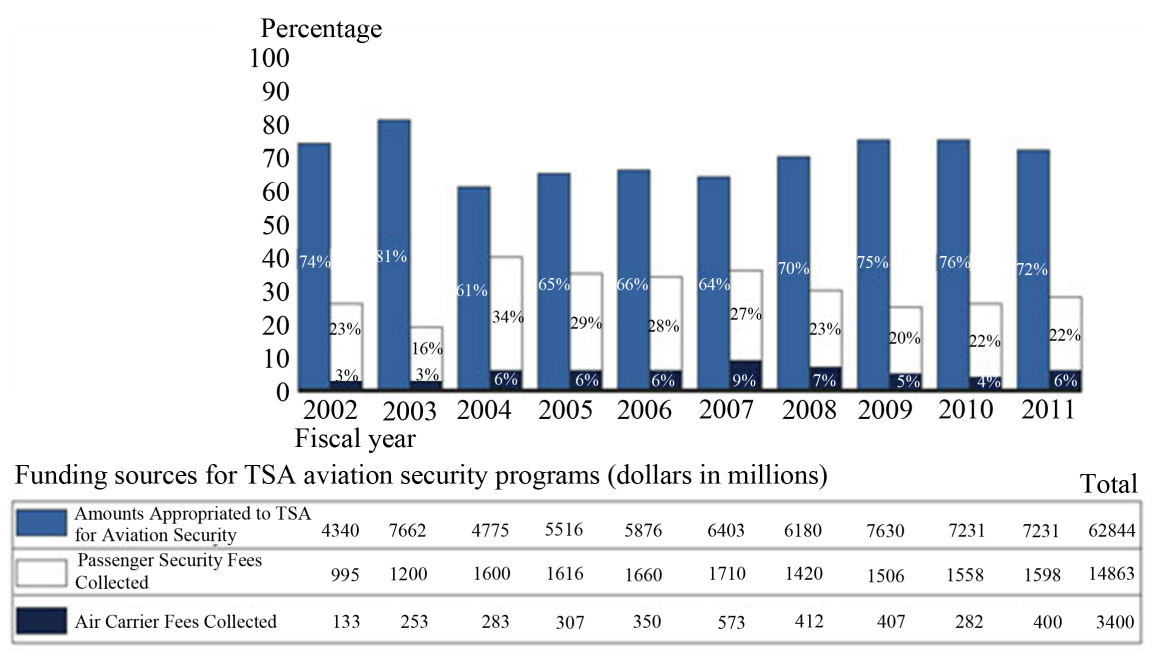

Source: GAO analysis of TSA data.

Figure 5. Transportation security administration total expenditures (\$US millions) (US government accountability office, n.d.).

There are four main mechanisms that are currently being used to fund aviation security activities within Europe:

- State aviation security taxes

- Airport security charges

- Carrier security surcharges or fees

- State grants and subsidies

From 2002 to 2018, the European total expenditure on security has raised from $\$ 2.66$ billion to $\$ 6.44$ billion, nut a breakdown for each of the expenditures listed above has not been found.

\section{Methodology}

\section{Performance in the United States}

Measuring the performance of the aviation security in the United States is difficult. Aviation security is inherently classified as it deals with threats to the aviation security system. There is no current way to look up how many threats per year the TSA stops or how many terrorists they capture. Furthermore, in the United States, only the TSA failings to prevent terrorist attacks are reported. The US has not had a major terrorist attack since 9/11. The information explored in this paper is "how much are we currently spending annually to save one life?"

A City Lab report states that the TSA is 95\% ineffective (Capps, 2015). ABC News reports that TSA agents failed to detect in 67 out of 70 trail runs (Fishel et al., 2015). In these trial runs, the US Department of Homeland Security performed a test where "Red Teams", disguised as passengers, were able to carry weapons and fake explosives through security check points without any trouble (Matthews, 2016). Using this inefficiency, an annual cost per life saved for the aviation security system can be estimated by the following model (Fishel et al., 2015). 


$$
\begin{gathered}
C_{l . s}=\frac{C_{R}}{\text { lives saved due to enhanced security measures }} \\
C_{l . s}=\frac{100 * C_{R}}{R * \text { fatality rate before enhanced security measures }}
\end{gathered}
$$

$C_{l . s}=$ Annual cost per life saved

$C_{R}=$ Annual cost spent on enhanced security measures

$R=$ pre boarding security rating $\mathrm{x}$ efficiency of TSA

Fatality rate before enhanced security measures $=300$ people per year

The one critical assumption that needs to be made is the fatality rate before enhanced security measures. There is no true way of knowing this fatality rate within the US before 2001 because there were no deaths due to hijacking before then. Researchers Mark Stewart and John Mueller have reached the assumption of 300 people based on the pre-9/11 conditions. They used the period of increased threat from Al-Qaeda, 1992-2001 to suggest that an event like the 9/11 would happen every 10 years, providing the annual fatality rate assumption of 300 people per year.

The study that Stewart et al. performed calculates the annual cost per life saved for the enhanced TSA security checkpoints (Stewart \& Mueller, 2014). Currently the TSA security checkpoints of "Aviation Screening Operations" cost the TSA about $\$ 5$ Billion. When determining the R-value, the pre-boarding security rating and the TSA efficiency should be considered. Stewart and Mueller described how they came up with their pre-boarding security rating R:

"The extra and more vigilant intelligence, immigration and passport control, airport screening, and other pre-boarding security measures implemented since 9/11 as arrayed in the TSA's 14 layers of security should result in an increased likelihood of detection and apprehension of terrorists. Increased public awareness is also of significant benefit to aviation security. These measures by themselves reduce the risk of a replication of the $9 / 11$ by at least $50 \%$, and this is likely to be a lower bound value. There has been no successful hijacking anywhere in the world since the 9/11 and very few attempts at blowing up airliners - and none of these in the United States. In consequence, we suspect, $R$ (pre-boarding security) is likely to be much greater than $50 \%$. Nonetheless, for the present analysis assume $R$ (pre boarding security) $=50 \%$."

The TSA efficiency rating was presented in the Report from ABC news as $5 \%$ effective or $95 \%$ ineffective.

When plugging into the Equation (2) we get:

$$
C_{l . s}=\frac{100 * C_{R}}{R * 300}=\frac{100 * 5 * 10^{9}}{(50 \% * 0.05 \%) * 300}=\$ 667 \text { millions }
$$

So, this means that on average, $\$ 667$ Million dollars per life saved are spent for enhanced TSA security checkpoints. According to the researchers, a regulatory safety goal of cost per life saved in the $\$ 1-\$ 10$ million range passes the cost-benefit threshold for most federal agencies. Based on this figure, it looks 
like we are spending too much on our security. However, when incorporating different values into this equation, it shows the differences based on efficiency rating. The chart below shows different input values and their result for the equation above (Table 3 ).

Figure 6 shows that as the R efficiency rating increases, the annual cost per life saved decreases. However, the results do not indicate that TSA Checkpoints are $95 \%$ ineffective. A reasonable and conservative assumption on the ineffectiveness of our TSA Checkpoints, as detailed by Stewart et al. should be $50 \%$. Looking at the data above, if the pre-boarding security rating was still 50 and the effectiveness of the TSA was 50\%, the cost per life saved would be $\$ 66$ Million. This is substantially less than the $\$ 667$ Million value that was calculated based to the $5 \%$ effective report. An adequate goes from $\$ 16$ Million (which is complete security and effectiveness) to $\$ 133$ Million (which is a pre boarding rating of 50 and a $25 \%$ effectiveness). There are, however, still doubts that the performance

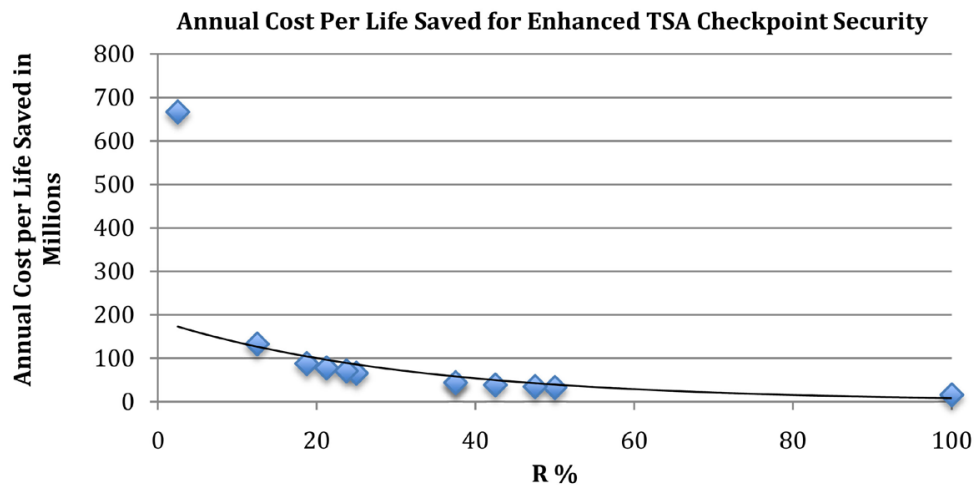

Figure 6. Annual cost per life saved for enhanced TSA checkpoint security.

Table 3. $C_{l . s}$ vs. pre-boarding security rating \&TSA efficiency chart.

\begin{tabular}{cccccc}
\hline $\begin{array}{c}\text { Pre-Boarding } \\
\text { Security Rating }\end{array}$ & $\begin{array}{c}\text { TSA } \\
\text { efficiency }(\%)\end{array}$ & R value & Cr value & $\begin{array}{c}\text { Fatalities } \\
\text { per year }\end{array}$ & $\begin{array}{c}\text { C life Saved } \\
\text { (\$ millions) }\end{array}$ \\
\hline 50 & 0.05 & 2.5 & $5,000,000,000$ & 300 & 667 \\
50 & 0.25 & 12.5 & $5,000,000,000$ & 300 & 133 \\
50 & 0.5 & 25 & $5,000,000,000$ & 300 & 66 \\
50 & 0.75 & 37.5 & $5,000,000,000$ & 300 & 44 \\
50 & 1 & 50 & $5,000,000,000$ & 300 & 33 \\
75 & 0.25 & 18.75 & $5,000,000,000$ & 300 & 88 \\
75 & 0.5 & 37.5 & $5,000,000,000$ & 300 & 44 \\
85 & 0.25 & 21.25 & $5,000,000,000$ & 300 & 78 \\
85 & 0.5 & 42.5 & $5,000,000,000$ & 300 & 39 \\
95 & 0.25 & 23.75 & $5,000,000,000$ & 300 & 71 \\
95 & 0.5 & 47.5 & $5,000,000,000$ & 300 & 35 \\
100 & 1 & 100 & $5,000,000,000$ & 300 & 16
\end{tabular}


of the TSA checkpoint is good enough even with the adjusted $\mathrm{R}$ ratings provided above. The annual cost per life saved can be limited by increasing the TSA efficiency and decreasing the annual cost spent on enhanced security measures. This cost-benefit analysis can be performed on individual portions of the TSA security enhancements, such as the Air Marshal Program, which was found to fail the cost-benefit threshold, and the Reinforcement of Cockpit doors, which were found to be cost-effective.

\section{Results and Analysis}

\section{U.S. vs. Europe}

The United States and Europe are good comparisons when it comes to aviation security, as they are both heavily traveled aviation destinations. Thus, it is important to understand how both regions perform on aviation security. However, performance measures for Europe were not easy to find. This study only discusses how each region is modeled and how much revenue each region generates to support their spending.

The US has followed the centralized model for aviation security since November 2001 where the Federal government (through the TSA) assumed responsibility for the key security activities at US airports. In Europe there is not just one model that runs the aviation security. There are some states within Europe that follow the centralized model, like the US, where the main security activities are paid for by the state via a government body. The rest of the states follow the decentralized model, which means that the main security activities are provided by the airport authorities ( $3^{\text {rd }}$ party) under the supervision of the state. EU is dominated by the public-private partnerships that control the implementation of aviation security standards.

In the US, remuneration of key security activities is paid for primarily by the TSA out of Federal funds. In Europe, Security activities are remunerated by a combination of stakeholders, including airports, air carriers, passengers and the States themselves. Currently the United States and Europe both have taxes to produce revenues to spend on their aviation security. After 9/11, the U.S. implemented the "9/11 Security Tax", which was a fee of $\$ 2.50$ each way of a trip on top of the price of a plane ticket. In 2014, the 9/11 Security Tax was increased to $\$ 5.60$ each way. So, for a round trip this fee would cost $\$ 11.20$ (Surry, 2014). In 2017, President Trump proposed a further increase to $\$ 6.60$, but this increase has not been established. The US also implemented an exercise tax that is a 7.5\% tax on airlines (TSA, n.d. Security Fee). This $7.5 \%$ is also added on top of the price of the ticket. Figure 7 shows how these old taxes affected the flight tickets and the influences of the new 9/11 Security Tax on tickets.

Still, these taxes do not generate enough revenue with respect to the amount the US is spending for security. In Figure 8, how much the US is spending in 2017 and how much of it is covered by tax revenues are presented.

The TSA is generating only about $1 / 3$ of its annual budget spending through 


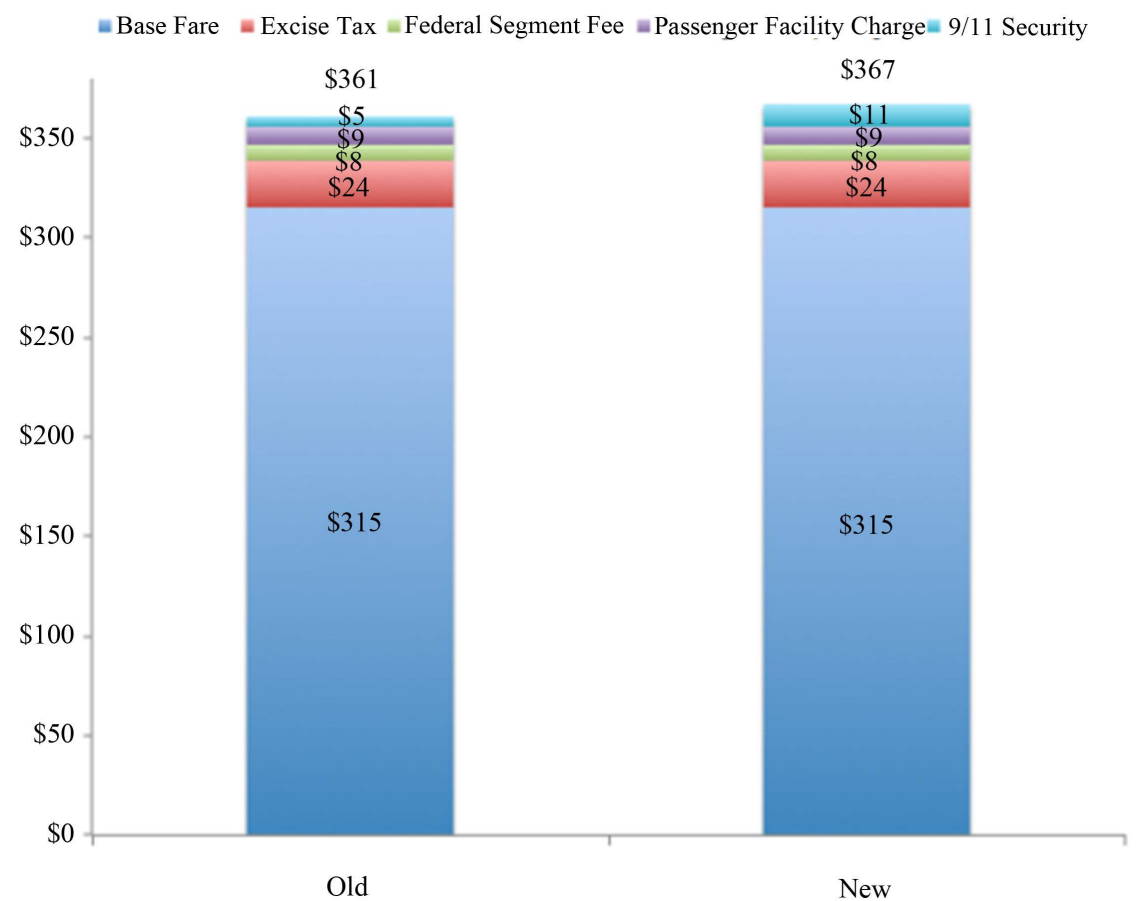

Figure 7. Ticket prices before and after the new 9/11 tax (Surry, 2014).

\begin{tabular}{|c|c|}
\hline \multicolumn{2}{|c|}{ Passenger Fee } \\
\hline Fiscal Year & Total Collection \\
\hline 2002 & $\$ 995400000$ \\
\hline 2003 & $\$ 1199700000$ \\
\hline 2004 & $\$ 1600200000$ \\
\hline 2005 & $\$ 1866300000$ \\
\hline 2006 & $\$ 1855800000$ \\
\hline 2007 & $\$ 1959800000$ \\
\hline 2008 & $\$ 1920100000$ \\
\hline 2009 & $\$ 1756000000$ \\
\hline 2010 & $\$ 1808000000$ \\
\hline 2011 & $\$ 1847500000$ \\
\hline 2012 & $\$ 1877700000$ \\
\hline 2013 & $\$ 1878900000$ \\
\hline 2014 & $\$ 2087000000$ \\
\hline 2015 & $\$ 3508200000$ \\
\hline 2016 & $\$ 3694217000$ \\
\hline 2017 & $\$ 3882602000$ \\
\hline 2018 & $\$ 4098503000$ \\
\hline
\end{tabular}

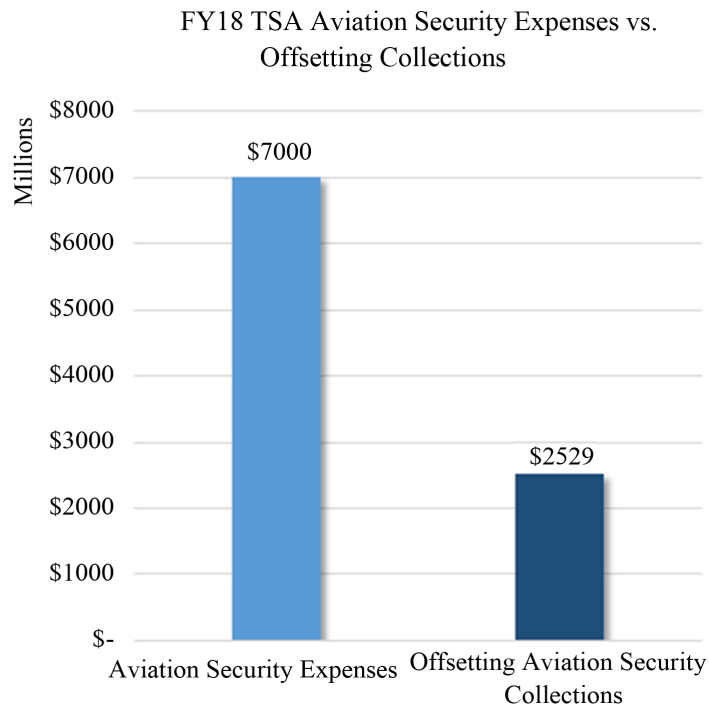

Figure 8. Historical collections chart and table (TSA, n.d. Security Fee).

passenger fees, which is costing the Federal government a large sum of money. On top of that, their expenses are also increasing. In 2002, the TSA spent $\$ 2.7$ Billion on aviation security. Now in 2018 the TSA is spending \$7.6 Billion on aviation security. In 2002 the European total expenditure cost for aviation security was 2.66 Billion US\$, and that number rose to 6.44 Billion US\$ by 2018 . According to Reuters, Airports Council International (ACI) predicts that European airports will need to invest about $\$ 17$ billion in order to meet EU baggage screening requirements by 2022 (Brian, 2018). However, for now, the TSA 
and European expenditures are very similar and have both increased dramatically over the years.

Both regions also generated about half of the amount that they spent in 2002 through taxes revenues. But in 2018, the United States and Europe had only generated about $1 / 3$ and $40 \%$ respectively of the amount they spent through tax revenues. Figure 9 presents a sample of how airport security charges differed from 2001 to 2003 in various European airports.

\section{U.S. vs. Canada}

In Canada, the federal government created the Canadian Air Transport Security Authority (CATSA) as an independent agency to test and implement new security technologies and oversee the training and standards of security personnel. Unlike the U.S., under the Canadian model, private market firms supply security personnel. The Canadian government instituted its own federal tax on air passengers; the "air travelers security charge" (ATSC) (Canada Revenue Agency, 2010). However, in contrast to the U.S., the tax was intended to cover all of CATSA's expenditures. Thus, the relative financial burden facing air passengers versus all citizens in Canada is very different than in the U.S. Since 2018, the current ATSC tax is $\$ 26$ for a round trip and $\$ 13$ for a one-way trip. Figure 10 shows CATSA's expenditures for aviation security, which can be compared to the total TSA expenditure that was shown in Table 1.

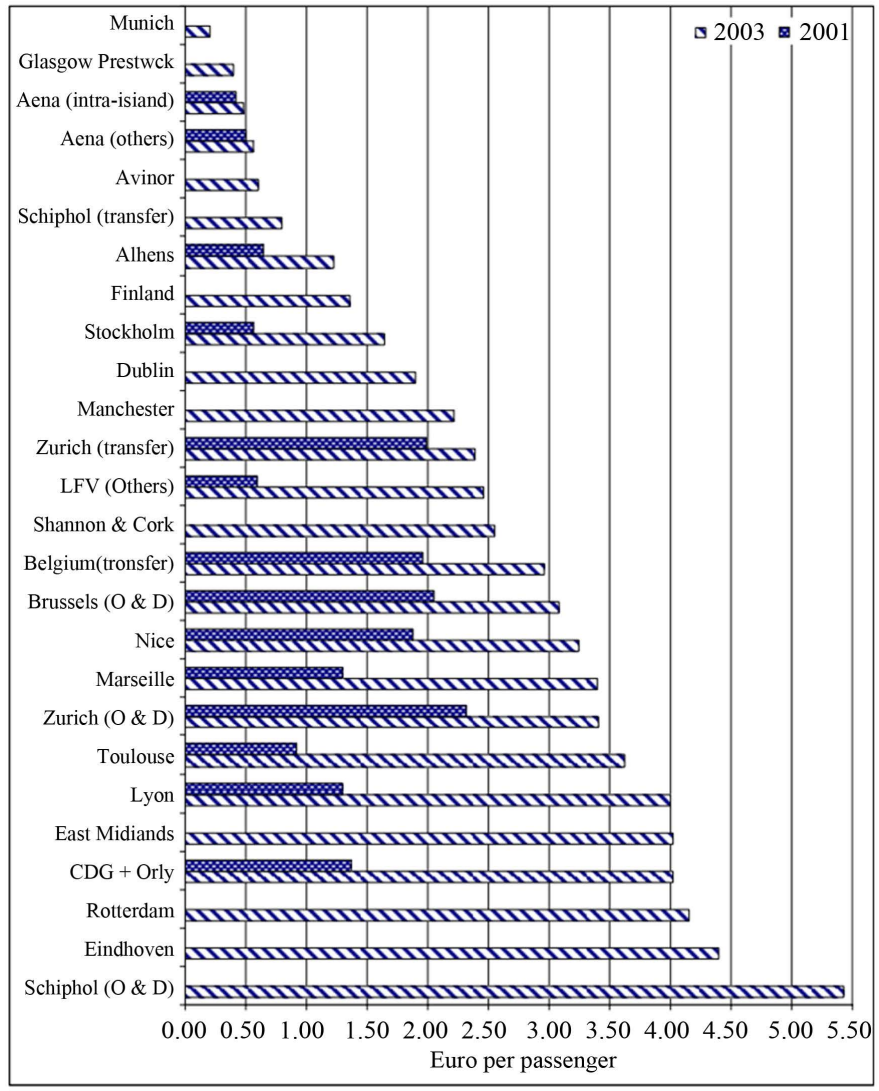

Figure 9. Sample of airport security charges 2001 vs. 2003 (Irish aviation authority, 2004). 


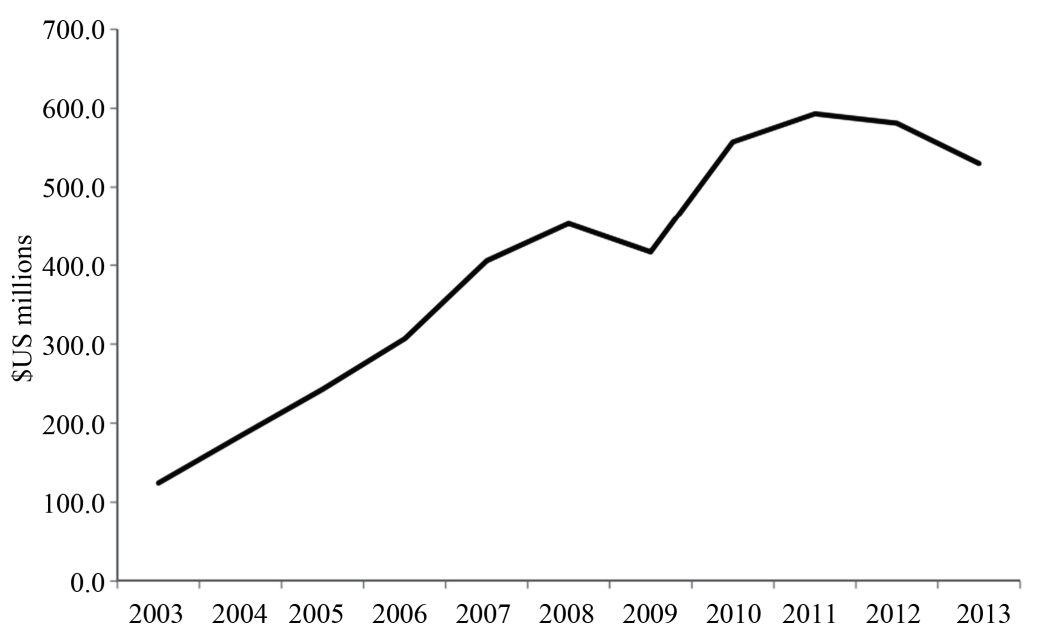

Figure 10. Total CATSA (Canada) expenditure in \$US (Gillen \& morrison, 2015).

In 2013, the TSA spent $\$ 7.5$ Billion dollars while CATSA only spent $\$ 550$ Million dollars. The Unites States is a much more heavily traveled country than Canada. The US also has many of the top airports in the world, so this difference in total expenditures is reasonable.

A further comparison is conducted for the amount each agency spends per capita. Throughout the ten-year period between 2005 and 2014, the TSA spent about $\$ 10$ - \$15 more per capita than the CATSA. For example, in 2014, the TSA spent about $\$ 22$ dollars per capita in the United States, while the CATSA only spent about \$12 dollars per capita in Canada (Gillen \& Morrison, 2015).

This may seem like a huge difference, but this comparison of spending per capita does not tell the entire story. When going further into the statistics, the expenditures per passenger screened is found to be close. When comparing expenditures per screened passengers for the TSA and the CATSA, the values are much closer, usually within $\$ 3$ of each other. In 2014, the TSA expense per passenger was about $\$ 11$, while the respective CATSA value was around $\$ 9$.

The per passenger expenditures for the TSA and CATSA are much closer than compared to the total expenditures per capita. The United States is a larger country than Canada and has greater aviation passenger traffic. The TSA's Budget is so much larger than the CATSA's because of the amount of air travelers they need to process. Although the TSA spends much more than the CATSA, both agencies seem to spend a similar amount per screened passenger.

However, the major difference between these two agencies is the amount of revenue they generate through taxes. The TSA only generates about $1 / 3$ of its entire spending through taxes or security fees, while the CATSA generates all of its spending from tax revenue. The total expenditures vs. revenue breakdown for the TSA from 2002 to 2011 can be found earlier in Figure 4, which shows 20\% $30 \%$ of the spending coming from passenger security fees and only $3 \%-10 \%$ coming from air carrier fees. The CATSA expenditures, compared to its generated revenue, can be seen in Figure 11. 


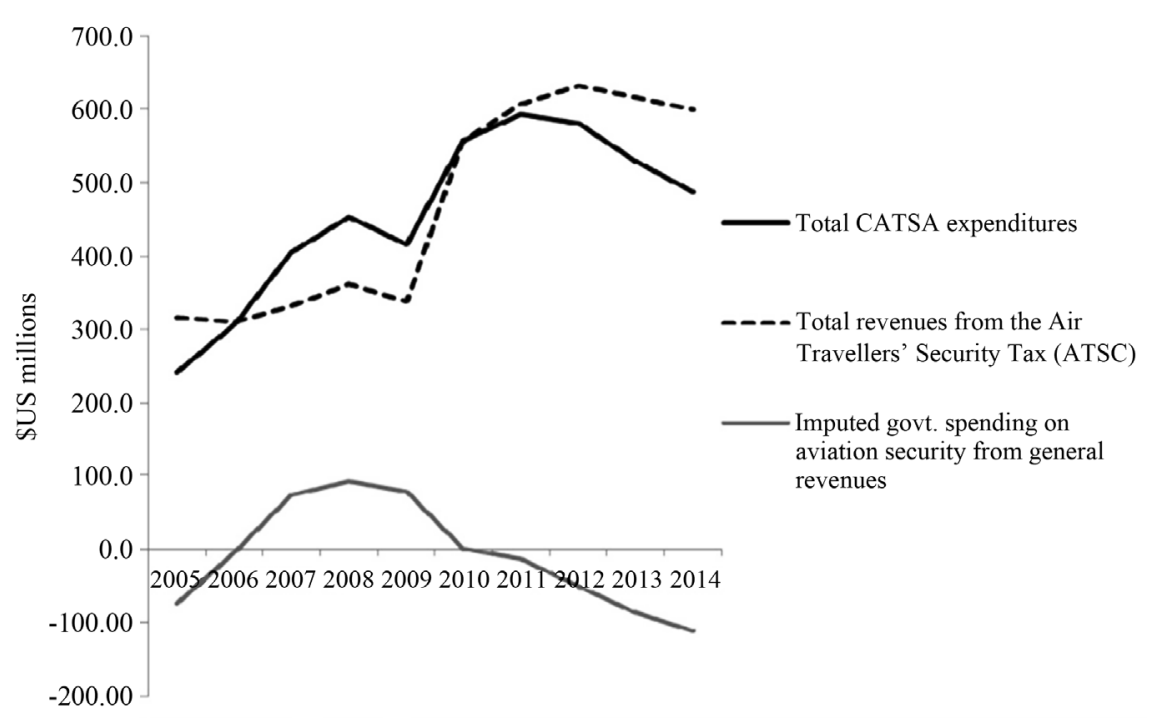

Figure 11. CATSA total expenditure, revenues from security and imputed government spending on aviation security (Gillen \& Morrison, 2015).

As shown above, the CATSA generates all of its expenditures via the ATSC. In fact, during some periods, such as after 2010, as shown in the figure, the CATSA generated more revenues than they spent. However, in Canada, the revenue generated from the ATSC goes into the national Consolidated Revenue Fund, which is then allocated among many sectors as appropriated by the Parliament of Canada (Canadian Airports Council, 2015). Table 4 shows the trends in CATSA passenger screening numbers, government funding, and ATSC revenues from 2010-2014.

Since the ATSC Revenue generated was surpassing the expenses required, the Canadian government began to decrease CATSA funding, but this caused the ATSC revenue to not be fully used for its purpose of funding security operations. After 2013, passenger volumes increased by $30 \%$ in five years, and continued funding decrease with respect to the operation expenses required to screen more passengers led to longer wait times, poorer security measures, and ultimately, led to CATSA expenses overtaking government funding. In 2019, many Canadian airports made plans to replace CATSA with privatized security since the funding model was no longer working as intended (How Privatizing CATSA Became the Only Choice, 2019).

Still, overall in this entire time period, ATSC revenue generated has been able to fund near or above $100 \%$ of CATSA expenditures, and just like the US, there was no major aviation attack after 9/11 in Canada. Comparatively, in the US, the government had to input $2 / 3$ of the total TSA budget. This revenue collected by the TSA is some of the lowest in the entire world. Figure 12 shows how the TSA's revenues compare to other countries. The US has the least value in Revenue per Passenger, shown by the dashed grey line that that lies significantly lower than all the other countries in the figure below. 


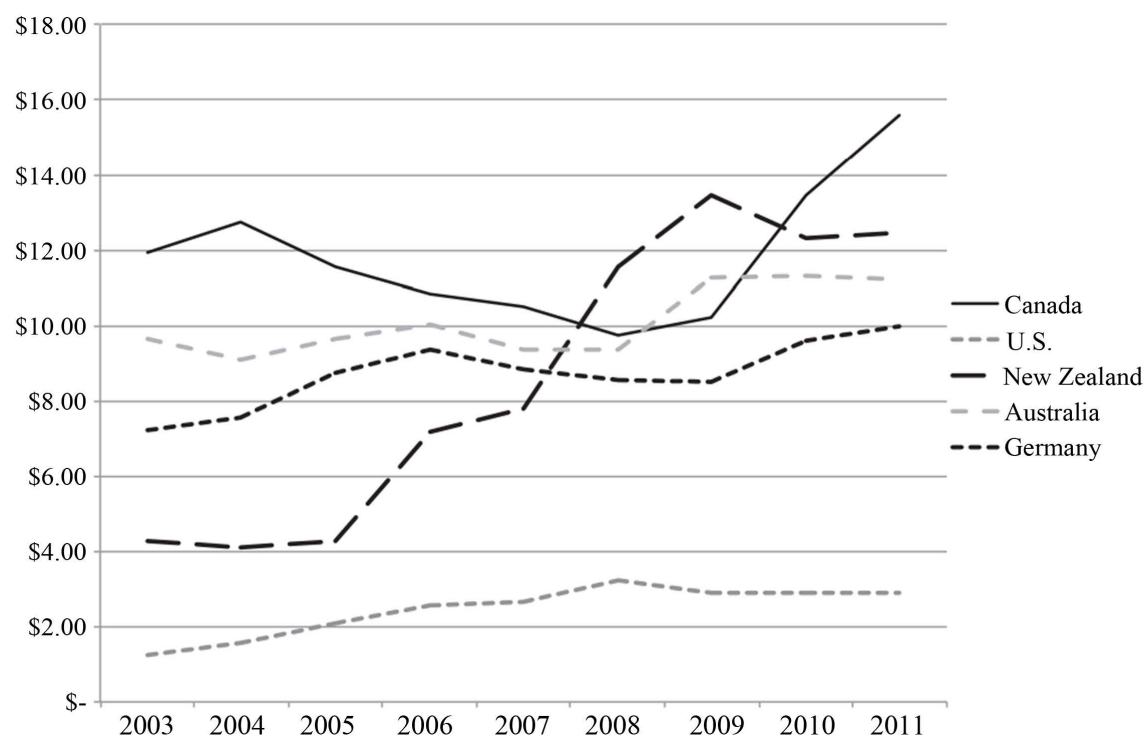

Figure 12. International comparison of revenue per passenger from security fee (Gillen \& Morrison, 2015).

Table 4. Canadian aviation security metrics $(2010-2014)^{53}$.

\begin{tabular}{ccccc}
\hline & $2010 / 2011$ & $2011 / 2012$ & $2012 / 2013$ & $2013 / 2014$ \\
\hline Total Passengers Screened in Millions & $47.7 \mathrm{M}$ & $49.0 \mathrm{M}$ & $51.0 \mathrm{M}$ & $53.9 \mathrm{M}$ \\
ATSC Revenue in Millions & $\$ 600.0 \mathrm{M}$ & $\$ 631.0 \mathrm{M}$ & $\$ 635.6 \mathrm{M}$ & $\$ 662.0 \mathrm{M}$ \\
Average ATSC per Screened Passenger & $\$ 12.57$ & $\$ 12.87$ & $\$ 12.46$ & $\$ 12.28$ \\
Total Gov. Funding for CATSA in Millions & $\$ 598.4 \mathrm{M}$ & $\$ 584.4 \mathrm{M}$ & $\$ 549.9 \mathrm{M}$ & $\$ 538.9 \mathrm{M}$ \\
CATSA Funding as Percentage of ATSC & $99 \%$ & $92 \%$ & $86 \%$ & $81 \%$ \\
\hline
\end{tabular}

\section{Summary \& Recommendations}

The United States, European countries, Canada, and most other countries redesigned their aviation security sectors after $9 / 11$. The US does spend the most money in aviation security, but as a whole, the European Union is not far behind. At first glance the Unites States appears to be spending more, but the conclusion changed after comparing the TSA expenditures to Europe and Canada. Europe is spending nearly just as much as the TSA; the CATSA is also spending a similar amount per screened passenger as the TSA. The areas in which these countries differ are the amount of revenue generated to support the expenditures. The Unites States does not generate enough revenue through taxes to support its TSA's expenditures.

The TSA may need to find alternative ways of increasing the amount of revenue raised. President Trump has called for increasing the 9/11-security fee about $17 \%$ but this is still not enough for covering the whole spending (Silk, 2017). If the 9/11-security fee was raised from $\$ 5.60$ to $\$ 7.60$, an additional $\$ 1.2$ Billion dollars will be earned. This could allow the revenues to cover almost $50 \%$ of the expenditures from the TSA. Another recommendation here is for the TSA to cut 
the air marshal program completely. Currently air marshals are only on $10 \%$ of all United States flights. The Program costs the TSA about $\$ 900$ Million dollars per year. Cost-benefit analysis of this program shows it is not high enough to be spending $\$ 900$ Million Dollars. If this program terminated entirely, the TSA expenditures would drop from $\$ 7.5$ Billion to $\$ 6.6$ Billion. Some of the money saved by cutting the air marshal program could be used to support other areas, such as funding research for new technologies to improve the passenger screening process.

However, the challenge of raising more revenue to support TSA expenses becomes even more vital considering that the quality of TSA workers must be improved. As seen before, screening workers can be improved to identify more security threats by increasing pay, training, and decreasing turnover rates in order to ensure more experienced airport security groups (Fish, 2003). Additionally, the TSA and USDHS may address the expenses by finding ways to produce more cost-effective technology, as well as using a risk-based security approach which is used in many European countries.

In this risk-based approach, an example would be a tiered baggage screening approach, where only suspicious baggage that may set off alarms at initial security checkpoints goes through further checkpoints. This is much better use of resource allocation, and speeds up passenger inflow (Poole \& Butler, 2002). Another idea is having a tiered passenger screening system that identifies and separates low and high-risk passengers and screening them according to their risk level (Poole, 2009). One of the ways to do this is having a program for frequent "trusted travelers" that allows them to bypass a layer of security, which has been proven to speed up screening times. The TSA has tried to implement this with the Registered Traveler program, but the minimal background check requires these travelers to still go through the same security checkpoints as every other passenger. Overall, there is not enough risk analysis, and risk analysis studies must be conducted so that legislators enact laws allowing individualized security measures for airports of different sizes, locations, and traffic.

\section{Future Research}

There are many more areas that need future research. It remains difficult to find specific information about international aviation security. If more research and information on international issues are available, a better comparison between the United States and others for aviation security systems could be achieved. This would enable us to make recommendations about which security model is the most effective or how to plan the expenditure. However, there are obvious limitations when it comes to the availability of security information. Much of the information on our security systems and how they work must be classified for national safety. Additionally, many international governments and security authorities are not likely to release their security data or allow anyone to conduct studies on their aviation security, which makes it hard for researchers to compare aviation security in different countries. 
Also, there are doubts in the TSA's screening technology for the lack of effectiveness and reliability on some issues, such as screening firearms (Lucky, 2017; Soller, 2017; TSA, 2020). Thus, some more areas of research would be for technology. There are new technologies that are being discussed, but many of them are still in the stage of experiment. The technology industry is extremely important with regards to the aviation security industry. However, similar to international aviation security data, security technology will also be restricted between governments and associated technology companies that are creating these technologies. The effectiveness of these newer technologies will most likely not be publicly available, but understanding how they will work may provide insight on how to implement them to improve security effectiveness and efficiency. By learning more about the new technologies, more technical-based recommendations could be provided for how to implement these into the US security system.

\section{Conflicts of Interest}

The authors declare no conflicts of interest regarding the publication of this paper.

\section{References}

ACI, Airports Council International (2019). Preliminary World Airport Traffic Rankings Released. https://aci.aero/news/2019/03/13/preliminary-world-airport-traffic-rankings-released

Bachman, J. (2002). Argenbright Security Screening Firm Departing US Airports in Disgrace, Las Vegas Sun.

https://lasvegassun.com/news/2002/apr/30/argenbright-security-screening-firm-depart ing-us-a

Blalock, G., Kadiyali, V., \& Simon, D. H. (2007). The Impact of Post-9/11 Security Measures on the Demand for Air Travel. Journal of Law and Economics, 50, 731-755. https://doi.org/10.2139/ssrn.677563

Bolluyt, J. (2018). These Are the Most Surprising Things You Could Do at an Airport Before 9/11. Showbiz CheatSheet.

https://www.cheatsheet.com/culture/things-you-could-do-at-an-airport-before-9-11.ht $\underline{\mathrm{ml}}$

Bouldon, J. (2002). Air Security to Get Even Tighter. CNN.com. http://edition.cnn.com/2002/WORLD/europe/09/10/ar911.airport.security

Brian, V. (2018). European Airports Face 15 Billion Euros in Extra Security Costs. Reuters.

https://www.reuters.com/article/us-europe-airports/european-airports-face-15-billioneuros-in-extra-security-costs-idUSKBN1JG2KA

BTS, Bureau of Transportation Statistics (n.d.). Average Cost of Airfare for Domestic Flights. https://www.bts.gov/archive/publications/passenger travel/chapter4/figure4-5

Canada Revenue Agency (2010). Notice to All Air Carriers-Rate Increases for the Air Travelers Security Charge. CANADA.ca. https://www.canada.ca/en/revenue-agency/services/forms-publications/publications/et $\underline{\text { sl72/notice-air-carriers-rate-increases-air-travellers-security-charge.html }}$

Canadian Airports Council (2015). Supplementary Submission to the CTA Review on 
Aviation Security Screening in Canada.

https://www.tc.gc.ca/eng/ctareview2014/pdf/Canadian\%20Airports\%20Council\%20Sup plement-Security\%20Screening.pdf

Capps, K. (2015). Airport Security: Astoundingly Expensive and 95 Percent Ineffective. CityLab.

https://www.citylab.com/transportation/2015/06/airport-security-astoundingly-expensi ve-and-95-percent-ineffective/394778

CATSA, Canadian Air Transport Security Authority (n.d.). About Us. https://www.catsa-acsta.gc.ca/en/about-us

EC, European Commission (n.d.). Aviation Security. European.eu. https://ec.europa.eu/transport/modes/air/security en

Elias, B. (2009). Airport and Aviation Security. Boca Raton, FL: Taylor \& Francis Group. http://file:///E:/Summer\%20Publications/Aviation\%20Reference/9780429249525 googl epreview.pdf https://doi.org/10.1201/9781420070309

Fish, M. (2003). Outside the U.S., a Different Approach to Air Security. CNN.com. http://edition.cnn.com/SPECIALS/2001/trade.center/flight.risk/stories/part3.mainbar.h $\underline{\mathrm{tml}}$

Fishel, J., Thomas, P., Levine, M., \& Date, J. (2015). EXCLUSIVE: Undercover DHS Tests Find Security Failures at US Airports. ABC News.

https://abcnews.go.com/US/exclusive-undercover-dhs-tests-find-widespread-security-f ailures/story?id=31434881

GAO, US Government Accountability Office (n.d.). Homeland Security/Law Enforcement, 48. Passenger Aviation Security Fees, GAO.gov.

https://www.gao.gov/modules/ereport/handler.php?1=1\&path=/ereport/GAO-12-342S P/data center savings/Homeland security--Law enforcement/48. Passenger Aviatio n Security Fees

Gillen, D., \& Morrison, W. G. (2015). Aviation Security: Costing, Pricing, Finance and Performance. Journal of Air Transport Management, 48, 1-12.

https://doi.org/10.1016/j.jairtraman.2014.12.005

Gittens, A. (2019). In the Balance: Global Air Transport Demand in 2018 and 2019. International Airport Review.

https://www.internationalairportreview.com/article/101952/world-airport-traffic-repor t-preview-aciworld

Gordon, P., Kim, S., Moore, J. E., Park, J., \& Richardson, H. W. (2005). The Economic Impacts of a Terrorist Attack on the U.S. Commercial Aviation System. Risk Analysis, 27, 505-512. https://doi.org/10.1111/j.1539-6924.2007.00903.x

Government of Canada (2011). Canadian Aviation Security Regulations, 2012. https://laws-lois.justice.gc.ca/eng/regulations/SOR-2011-318/FullText.html\#h-775762

Hainmüller, J., \& Lemnitzer, J. M. (2003). Why Do Europeans Fly Safer? The Politics of Airport Security in Europe and the US. Terrorism and Political Violence, 15, 1-36. https://doi.org/10.1080/09546550390449863

IAA, Irish Aviation Authority (2004). Study on Civil Aviation Security Financing. Irish Aviation Authority/Avia Solutions Group. https://ec.europa.eu/transport/sites/transport/files/themes/security/studies/doc/2004 0 9 study financing aviation security en.pdf

IATA, International Air Transport Association (2006). Economics Briefing: The Impact of the 9/11 Terrorist Attacks. 
https://www.iata.org/en/iata-repository/publications/economic-reports/impact-ofsept11th-2001-attack

International Civil Aviation Organization (n.d.). Air Transport, Passenger Carried. The World Bank. https://data.worldbank.org/indicator/IS.AIR.PSGR?most recent value desc=true

Jackson, B. A., \& Frelinger, D. R. (2012). The Problem to Be Solved: Aviation Terrorism Risk Past, Present, and Future. In Efficient Aviation Security: Strengthening the Analytic Foundation for Making Air Transportation Security Decisions (pp. 11-42). Santa Monica, CA: RAND Corporation. http://www.jstor.org/stable/10.7249/j.ctt3fgzzr.10

Katko, J. (2017). Checkpoint of the Future: Evaluation TSA's Innovation Task Force Initiative. TSA.gov.

https://www.tsa.gov/news/testimony/2017/04/27/checkpoint-future-evaluating-tsas-inn ovation-task-force-initiative

Lucky, B. (2017). The TSA Continues to Miss 95\% of Weapons-How Is This Okay? OneMileataTime.com. https://onemileatatime.com/tsa-fails-tests-95-percent

Matthews, D. (2016). The TSA Is a Waste of Money That Doesn't Save Lives and Might Actually Cost Them. VOX. https://www.vox.com/2016/5/17/11687014/tsa-against-airport-security

Maynard, M., \& Robbins, L. (2009). New Restrictions Quickly Added for Air Passengers. The New York Times. https://www.nytimes.com/2009/12/27/us/27security.html

National Commission on Terrorist Attacks upon the United States (2004). Complete 9/11 Commission Report. https://govinfo.library.unt.edu/911/report/index.htm

O'Connor, L. (2016). This Is What It Was Like to Go to the Airport before 9/11. Huffpost. https://www.huffpost.com/entry/airports-before-911 n 57c85e17e4b078581f11a133?g $\underline{\text { uccounter }=1}$

Oxley, D., \& Jain, C. (2015). Chapter 1.4 Global Air Passenger Market: Riding Out Periods of Turbulence, Travel and Tourism Competitiveness Report 2015. International Air Transport Association. World Economic Forum.

https://reports.weforum.org/travel-and-tourism-competitiveness-report-2015/chapter1-4-global-air-passenger-markets-riding-out-periods-of-turbulence

Poole, R. W. (2008). Toward Risk-Based Aviation Security Policy. Paris: OECD/ITF Joint Transport Research Centre Discussion Paper, No. 2008-23, Joint Transport Research Centre. https://doi.org/10.1787/228687543564

Poole, R. W. (2009). The Case for Risk-Based Aviation Security Policy. World Customs Journal, 3, 3-16.

http://citeseerx.ist.psu.edu/viewdoc/download?doi=10.1.1.738.5953\&rep=rep $1 \&$ type $=p$ $\underline{\mathrm{df}}$

Poole, R., \& Butler, V. (2002). Rethinking Checked-Baggage Screening. Los Angeles, CA: Reason Foundation. https://reason.org/policy-study/rethinking-checked-baggage

Seaney, R. (2019). 9 Ways Airport Security Changed Since 9/11. Farecompare.com. https://www.farecompare.com/travel-advice/9-ways-security-has-changed-since-911

Silk, R. (2017). Report: Trump Budget Calls for Hike in TSA Security Fee. TravelWeekly.com.

https://www.travelweekly.com/Travel-News/Government/Trump-budget-calls-for-hike -in-TSA-security-fee

Soller, G. (2017). Alarming Airport Security Holes: Are We Vulnerable to Another 
9/11-Type Attack? Forbes.com.

https://www.forbes.com/sites/garystoller/2017/08/15/alarming-airport-security-holesmight-another-911-type-attack-be-coming/\#62fd3afc44e9

Stewart, M. G., \& Mueller, J. (2014). Cost-Benefit Analysis of Airport Security: Are Airports Too Safe? Journal of Air Transport Management, 35, 19-28. https://doi.org/10.1016/j.jairtraman.2013.11.003

Surry, P. (2014). 9/11 Security Fee’ Increases to \$11.20 for Roundtrip Non-Stop. Hopper. https://media.hopper.com/research/911-security-fee-increases-11-20-roundtrip-non-st op

TSA, Transportation Security Administration (2017). Working to Protect You: Innovation Task Force. TSA.gov. https://www.tsa.gov/blog/2017/06/12/working-protect-you-innovation-task-force

TSA, Transportation Security Administration (2020). Number of Guns Brought to Airport Checkpoints in 2019 up 5 Percent. TSA.gov.

https://www.tsa.gov/news/releases/2020/01/15/number-guns-brought-airport-checkpoi nts-2019-5-percent

TSA, Transportation Security Administration (n.d.). Emerging Technology. https://www.tsa.gov/travel/security-screening/emerging-technology

TSA, Transportation Security Administration (n.d.). Mission, Transportation Security Administration. https://www.tsa.gov/about/tsa-mission

TSA, Transportation Security Administration (n.d.). Security Fee. https://www.tsa.gov/for-industry/security-fees

US Congress (2001). Aviation and Transportation Security Act. https://www.tsa.gov/sites/default/files/aviation and transportation security act atsa public law 107 1771.pdf

USDHS, Department of Homeland Security (2017). Transportation Security Administration Budget Overview: Fiscal Year 2018.

https://www.dhs.gov/sites/default/files/publications/TSA\%20FY18\%20Budget.pdf

USDHS, Department of Homeland Security (2019). Budget-in-Brief: Fiscal Year 2018. https://www.dhs.gov/sites/default/files/publications/DHS\%20BIB\%202019.pdf

USDOT, US Department of Transportation (2003). Budget in Brief: Fiscal Year 2003. Washington DC: US DOT.

https://www.transportation.gov/sites/dot.dev/files/docs/dot budget highlights fy 200 3.pdf

Vora, S. (2017). T.S.A. Testing 2 Technologies to Speed Airport Screening. The New York Times.

https://www.nytimes.com/2017/06/28/travel/tsa-testing-2-technologies-to-speed-airpor t-screening.html

Western Aviation News (2019). How Privatizing CATSA Became the Only Choice. WAN. https://westernaviationnews.com/2019/03/24/sunday-reader-catsa-replacement-privati zation-federal-budget-2019

Wikipedia.org (n.d.). Airport Security Repercussions Due to the September 11 Attacks. Wikipedia.

https://en.wikipedia.org/wiki/Airport security repercussions due to the September 11 attacks

Wikipedia.org (n.d.). Transportation Security Administration. Wikipedia. https://en.wikipedia.org/wiki/Transportation Security Administration 